\title{
Comparison of serological and clinical findings in turkish patients with cystic echinococcosis
}

\author{
A. YOLASIGMAZ ${ }^{1}$, K. REITEROVÁ, M. TURK ${ }^{2}$, E. REYHAN ${ }^{3}$, A. D. BOZDAG ${ }^{3}$, \\ A. O. KARABABA ${ }^{4}$, NURAY ALTINTAS ${ }^{5}$, NASMIYE ALTINTAS ${ }^{1}$
}

\begin{abstract}
${ }^{1}$ Ege University, School of Medicine, Department of Parasitology, İzmir, Turkey; *Parasitological Institute of the Slovak Academy of Sciences, Košice, Slovak Republic; E-mail: reiter@saske.sk; ${ }^{2}$ Atatürk Research and Training Hospital, Dept. of Microbiology, İzmir,Turkey, ${ }^{3}$ Atatürk Research and Training Hospital, Dept. of General Surgery, İzmir, Turkey; ${ }^{4}$ Ege University, School of Medicine, Dept. of Public Health, İzmir, Turkey; ${ }^{5}$ Celal Bayar University, School of Medicine, Department of Medical Biology and Genetics, Manisa, Turkey
\end{abstract}

\begin{abstract}
Summary
Cystic echinococcosis (CE), caused by the cestode Echinococcus granulosus, is potentially dangerous for humans. The aim of this study was to examine serological and clinical findings regarding cysts localisation and individual responses in 54 patients with CE. The majority of patients in this study were females $(63 \%)$ and the average age was 46.3 years. Most of the patients lived in rural areas or kept a $\operatorname{dog}(46 \%)$ for a long time. The most frequent symptoms were hypochondrial pain (48.9\%), epigastrial discomfort $(27.7 \%)$, vomiting $(21.3 \%)$, minor cough $(12.8 \%)$, urticaria $(6.3 \%)$, weakness $(4.3 \%)$, fever $(2.1 \%)$, side- or backache $(4.3 \%)$. However, $17 \%$ of the patients showed no symptoms. In every case, the ultrasound (USG) and/or computer tomography (CT) investigations were positive. In most cases (53.2\% of the patients) a single cyst was found but $46.8 \%$ of the patients had multiple cyst formations (from 2 to 9 cysts) located in the liver. Sporadic lung, splenetic, mesenterial, tibial and cerebral localisations were also found. The patients were individually treated with albendazol $(10-15 \mathrm{mg} / \mathrm{kg})$ five days prior and six months after the surgical treatment. Serum samples were investigated by the serological techniques: IHAT, ELISA and Western blot using hydatid fluid antigen. In the patient sera, the specific antibody levels were mostly increased after surgery. Different results were obtained only in two patients. In the first case, seroconversion was delayed. In the other case all ELISA results were negative, however, the Western blot analysis and surgery proved the presence of CE. The results suggest that the different antibody response of patients depends on the individual immune response. Multiple localization and various stages of CE cysts demonstrate the necessity of a complex approach for the confirmation of a correct diagnosis.
\end{abstract}

Key words: Echinococcus granulosus; cystic echinococcosis; clinical finding; serodiagnosis; Turkey

\section{Introduction}

Cystic hydatid disease is the larval cystic stage of a small tapeworm Echinococcus granulosus and is potentially dangerous for humans. It is an important public health problem in many regions of the world, both in endemic areas and in regions where the disease is emerging or re-emerging (Craig et al., 1996). New cases are mostly found in areas where dogs and livestock coexist. In primary echinococcosis, metacestodes develop from oncospheres after per-oral infection with E. granulosus eggs. In secondary echinococcosis, larval tissue proliferates after being spread from the primary site of the metacestode. This can occur by trauma such as spontaneous rupture of cyst or during medical interventions. Hydatid cysts have the ability to grow quite large and manifest as cysts especially in the liver $(65 \%)$ and lungs $(25 \%)$, but also in various organs including the brain, heart, bones, kidney and spleen (Gottstein \& Hemphill, 1997). Clinical manifestation depends on the localization and size of the cyst. Imaging techniques (US, CT) and serology provide both useful and complementary information on the character of the cyst that may be relevant for therapeutic intervention (Lightowlers \& Gottstein, 1995; Altintas et al., 1999a). Serological tests provide an extremely important information related to the diagnosis and prognosis of disease. Among the serological tests, the IgG-ELISA and IHAT are widely used for diagnosis and for monitoring the disease in the postoperative period (Force et al., 1992; Zarzosa et al., 1999; Rebhandl et al., 1999).

\footnotetext{
* Corresponding author
} 
The aim of this study was to compare serological and clinical findings regarding cysts localisation and individual serological responses in patients with cystic echinococcosis.

\section{Material and Methods}

\section{Patient sera}

Patients included in the study were hospitalised in Atatürk Research and Training Hospital Izmir, Turkey, from 2002 to 2004 . Sera from a total of 54 patients (48 with hepatic-, 1 with lung-, 1 with tibia-, 1 with cerebral-paraoxipital-, 1 with neck postcervical cystic echinococcosis, 1 patient with both, liver and spleen located cysts and 1 patient with multilocalisation of hydatid cysts in the liver, spleen and mesenterium were analysed. The majority of the patients had single cystic lesion situated in one lobe of the liver (usually in the right lobe). All sera were investigated by indirect hemaglutination test (IHAT) and enzyme linked immunosorbent assay (ELISA). Sera of four patients were examined before and after surgery. Biochemical, haematological and histological examinations of the patients were done by routine clinical laboratory methods. The US and CT examinations were also performed.

\section{Antigen}

Sheep hydatid fluid (HF) was collected from fertile cysts obtained from slaughterhouse. After centrifugation at 10 $000 \mathrm{~g}$ for $30 \mathrm{~min}$ at $4^{\circ} \mathrm{C}$, antigen was concentrated in an Amicon ultra filtration cell with a YM2 membrane (Amicon Corp., Bedford, USA) and kept at $-20^{\circ} \mathrm{C}$ for subsequent use.

Determination of Echinococcus-specific antibody production by IHAT

An indirect hemaglutination test (IHAT) was used according to the method described by Garabedian et al. (1957). Serial dilutions, starting at $1 / 8$ were examined and titer of $1 / 32$ or higher was considered positive.

Determination of Echinococcus-specific antibody production by ELISA

Standard indirect ELISA was carried out on polystyrene microtitre plates with 96 wells (F-Form; Maxisorp, Nunc, Roskilde, Denmark) coated with $100 \mu \mathrm{l} /$ well of hydatid fluid (at a concentration of $5 \mu \mathrm{g}$ of proteins per well) in carbonate-bicarbonate buffer, $\mathrm{pH} 9.6$, overnight at $+4^{\circ} \mathrm{C}$. Plates were then washed 3 times in $0.5 \%$ PBS Tween 20 (PBS-T) and blocked for 1 hour with $5 \%$ non-fat milk with PBS-T at $37^{\circ} \mathrm{C}$. Then $100 \mu \mathrm{l}$ of serum samples diluted $1 / 200$ in $5 \%$ non-fat milk with PBS-T were added and incubated for $1 \mathrm{~h}$ at $37^{\circ} \mathrm{C}$. After washing, horseradish peroxidase-conjugated anti-human IgG (Sigma, St.Louis, MO, USA) diluted 1/10000 was applied for $1 \mathrm{~h}$. After repeated washing, the chromogen o-phenylenediamine (Sigma) with $\mathrm{H}_{2} \mathrm{O}_{2}$ was added as substrate. The reaction was stopped with $0.5 \mathrm{M} \mathrm{H}_{2} \mathrm{SO}_{4}$ after 15 min. Optical densities (OD) were read spectrophotometrically at $492 \mathrm{~nm}$ (Thermo Labsystems Opsys MR, USA). Cut off values were determined by taking the average OD of negative control sera plus 3 standard deviations (SD).

\section{SDS-PAGE electrophoresis and Western blot analysis}

Sera of patients positive by ELISA were confirmed by the Western-blot technique. Electrophoresis (ELFO-SDS PAGE) was performed using a Bio-Rad Mini Protein Slab Cell (Bio-Rad Laboratories, CA, USA) on a $12 \%$ SDS-polyacryalmide gel and $4 \%$ stacking gel under reducing conditions (Laemmli, 1970). Hydatid fluid antigen from fertile cysts of sheep was electophoresed at $200 \mathrm{~V}$ for 1 hour at a room temperature. Low molecular weight markers (prestained SDS-PAGE standards, Bio-Rad) were included in each electrophoretic run. Following electrophoresis, proteins were transferred to nitrocellulose (NC) membrane in Tris-glycine buffer ( $\mathrm{pH} \mathrm{8.8)} \mathrm{at} \mathrm{constant} \mathrm{voltage} \mathrm{of} 250 \mathrm{~V}$ for 1 hour using a Bio-Rad Trans-Blot Cell. After blotting, the NC membrane was cut into $2.5 \mathrm{~mm}$ - wide strips and blocked with $5 \%$ bovine serum albumin in PBS (pH 7.2) for $30 \mathrm{~min}$ at $37^{\circ} \mathrm{C}$. Sera diluted $1 / 50$ with $5 \%$ bovine serum albumin in PBS were incubated for 1 hour at $37^{\circ} \mathrm{C}$. The strips were washed three times with PBS-Tween 20 and reacted with horseradish peroxidase conjugated anti human $\operatorname{IgG}$ in dilution of $1 / 500$ for 1 hour at $37^{\circ} \mathrm{C}$ with continuous shaking. Subsequently, the strips were washed again three times with PBS-Tween 20 and bands were developed using $0.05 \%$ 4-chloro-1-naphthol in PBS (pH 7.2) and $0.03 \%$ hydrogen peroxide.

\section{Data analysis}

The results were evaluated statistically by the $\chi^{2}$-test. The comparison of the two techniques was done using Fisher Exact test. The differences among the groups were considered significant at the values of $\mathrm{P}<0.05$.

\section{Results}

The $63 \%$ of the 54 analysed patients represented were females $(\mathrm{P}<0.05)($ Tab. 1$)$. The average age of the patients was 46.3 years (the youngest patient was 14 and the oldest 78 years old). Most of them lived in rural areas without significant differences $(\mathrm{P}>0.05)$ or kept a dog $(46 \%)$ for a long time.

The majority of the patients had from 1 to 9 of echinococcal cysts in the liver $(88.9 \%)$. In one case, with a high specific antibody response, the affected organ was lung and in other cases a single splenic-, mesenterial-, tibial and cerebral localisations were identified. In one case the patient died (73-year-old female with 2 cysts in the liver). The patients were individually treated with albendazol $(10-15$ $\mathrm{mg} / \mathrm{kg}$ ) usually five days prior and six months after surgical treatment.

In the patients examined prior and after the surgery positive ELISA remained at a high or even elevated. Despite of positive CE finding serological results in two patients were totally negative. In one ELISA negative patient, IHAT finding was low positive and Western blot confirmed the positive CE (Tab. 1). 
Table 1. Personal data and serological results of patients with cystic echinococcosis

\begin{tabular}{lccccccc}
\hline Patients & $\begin{array}{c}\text { Number of } \\
\text { examined }\end{array}$ & $\begin{array}{c}\text { Mean } \\
\text { age }\end{array}$ & $\begin{array}{c}\text { Residence } \\
\text { U/R }\end{array}$ & $\begin{array}{c}\text { Dog } \\
\text { ownership }\end{array}$ & IHA & $\begin{array}{c}\text { ELISA } \\
\text { Western } \\
\text { blot }\end{array}$ \\
\hline Male & 20 & 46.6 & $8 / 12$ & 10 & 19 & 19 & $6 *$ \\
Female & 34 & 45.5 & $17 / 17$ & 15 & 33 & 32 & $22^{* *}$ \\
\hline Total & 54 & 46.3 & $25 / 29$ & 25 & 52 & 51 & 28 \\
\hline
\end{tabular}

$\mathrm{U}$ - urban; R - rural; * samples of eleven patients not examined with WB; ** samples of nine patients not examined with WB

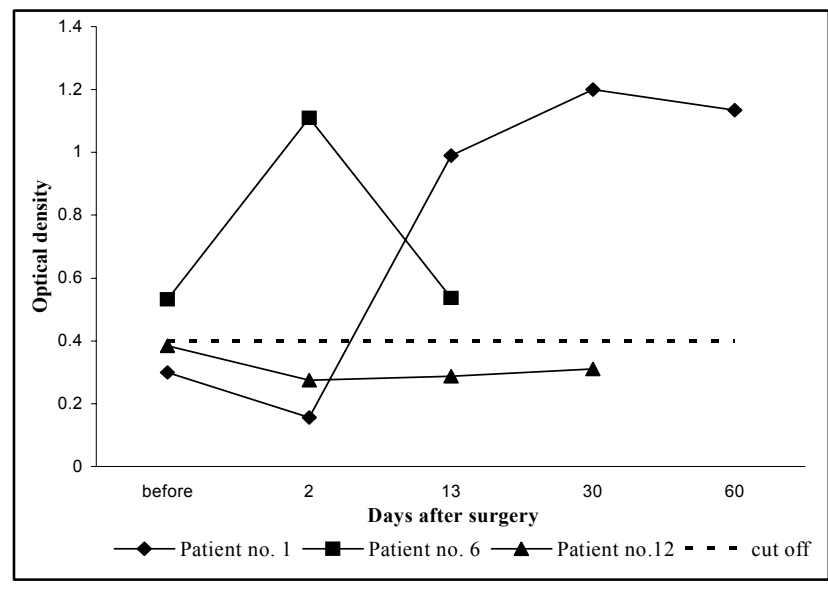

Fig. 1. Different outcome in specific echinococcal $\operatorname{IgG}$ antibodies after the surgical treatment

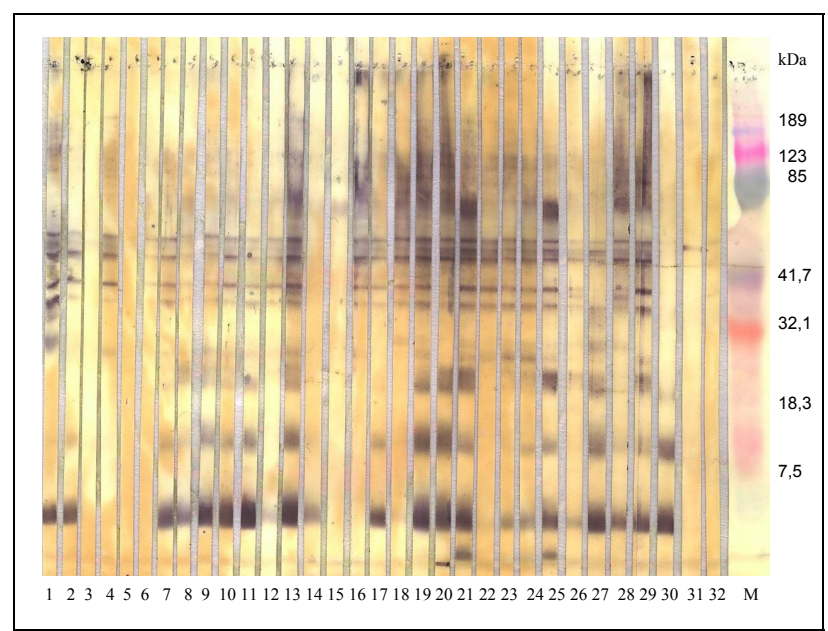

Fig. 2. Western blot analysis of selected patient sera The lines represented 1,2-positive control sera; 3,5 - negative control sera; 4, 6-31 patient sera showed in the Table 2; $32-$ patient with trichinellosis; $\mathrm{M}$ - marker

Following the specific antibodies kinetics in patient No.1 a delayed seroconversion and negative serological results were observed prior and two days after the surgery. The first positive results were found only two weeks after the surgery with an increasing level during the first and second month after the surgical treatment (Fig. 1). In contrast, antibody levels in patient no. 6 declined after the surgery. In patient No. 12, ELISA results were negative before and after surgical treatment. However, IHAT and Western blot analysis proved the presence of cystic echinococcosis. The results of Western blot analysis (Fig. 2) samples from selected patients are shown in the Table 2. These patients have different cysts localisation and serological results with confirmed CE.

According to the clinical findings the more frequent symptoms were hypochondrial pain $(48.9 \%)$, epigastrial pain (27.7\%), vomiting $(21.3 \%)$, cough $(12.8 \%)$, urticaria $(6.3$ $\%)$, weakness $(4.3 \%)$, fever $(2.1 \%)$, side- or backache $(4.3 \%)$, whereas $17 \%$ of the patients had no symptoms. In all cases, USG and/or CT examinations were positive.

\section{Discussion}

Diagnosis of CE in humans is not easy and depends on the diagnostic facilities available in hospitals and laboratories, as well as the anatomical localisation of cysts (Altintas \& Yazar, 1999). The clinical features of CE are highly variable. The spectrum of symptoms depends on the involved organs; size of the cysts and their sites within the affected organ or organs. Additionally the interaction between the expanding cysts and adjacent organ structures; or complications caused by rupture of the cysts; bacterial infection, spread of protoscolices and larval material into bile ducts or blood vessels may also considerably contribute to the outcome of CE (Brunetti \& Filice, 2005). In this study the echinococcal cysts were mostly localised in the liver. Seldomly the other organs as the lung, spleen, brain or bones were affected. In most cases, a single cyst was found (53.2 $\%$ ) but $46.8 \%$ of patients had multiple cyst formations with various numbers. The most frequent clinical symptoms were hypochondrial and epigastrial discomfort, vomiting, less often cough, urticaria, weakness, fever, side- or backache. However, in some cases (17\% of patients) clinical symptoms were absent. No correlation was found between clinical symptoms and specific antibody levels. In accordance with other authors (Kinčeková et al., 1996, Altintas et al., 1999b) the rural population showed a higher positivity than the urban population, as well as, significantly more women were infected in comparison to the men. The degree of antibody response to the cyst is mediated by its location and degree of calcification. Normally, liver cysts produce a higher antibody response than lung cysts (Craig \& Nelson, 1984; Gottstein, 1992; Ramos et al., 2001). While one patient from our study with lung CE showed high antibody response in all serological tests used three different antibody patterns were detected after the surgical treatment. A delayed seroconversion was found in 
Table 2. Site of infection and serological results of patients with confirmed CE (*results of the same patient within 2 weeks interval; ${ }^{+}$titer $1 / 32$ is considered as the positive threshold value; ${ }^{++}$cut off value is 0.440 )

\begin{tabular}{|c|c|c|c|c|}
\hline $\begin{array}{l}\text { No. of } \\
\text { strips in } \mathrm{Wb}\end{array}$ & Organ/number/ size of cysts (cm) & $\begin{array}{l}\text { IHAT } \\
\text { titres }^{+}\end{array}$ & ELISA-IgG OD $^{++}$ & Western blot $(\mathrm{kDa})$ \\
\hline 4 & liver/3/7, 6,8 & $1 / 1024$ & 1.314 & 28 \\
\hline 6 & liver/1/15.7x9x11;right lob & negative & 0.553 & negative \\
\hline 7 & liver $/ 1 / 4 \mathrm{x} 4$ & $1 / 32$ & 0.425 & $7,16-18$ \\
\hline 8 & cerebral - paraoxipital & $1 / 128$ & 0.985 & $8 ; 16-18 ; 26-28$ \\
\hline 9 & liver/1/ right lob $10 \times 10$ & $1 / 64$ & 0.538 & $7,16,18,26,28$ \\
\hline 10 & & $1 / 16$ & 1.280 & $8 ; 16-18 ; 26-28 ; 56-65$ \\
\hline 11 & $\begin{array}{c}\text { neck - postcervical } \\
5 \times 4\end{array}$ & $1 / 32$ & 0.623 & $8 ; 16-18 ; 26-28 ; 56-65$ \\
\hline 12 & liver & $1 / 32$ & 0.383 & $8 ; 26$ \\
\hline 13 & liver/2/ right lob $10 \times 8 \times 5 ; 1 \times 1$ & $1 / 256$ & 1.001 & $\begin{array}{c}8 ; 16-18 ; 26-28 ; 56-65 \text { strong } \\
\text { fuzzy band }\end{array}$ \\
\hline 14 & liver/3/ right lob $3 \times 4 ; 23 \times 3 ; 6 \times 3.5$ & $1 / 8$ & 1.100 & $7,16-18$ weak \\
\hline 15 & liver/1/ right lob /12x10 & $1 / 16$ & 0.320 & negative \\
\hline 16 & liver/1/ right lob/ $10 \times 8$ & $1 / 1024$ & 2.100 & above 35 \\
\hline 17 & liver & $1 / 128$ & 0.640 & 7,16 \\
\hline 18 & $\begin{array}{l}\text { liver/2 /right lob 9; } 9 \\
\text { spleen hilus/ 1 / 7x7 }\end{array}$ & $1 / 1024$ & 0.815 & 7,28 weak \\
\hline 19 & liver/ a few/ 5 right lob & $1 / 1024$ & 0.950 & $8 ; 16-18 ; 38 ; 26-28 ; 56-65$ \\
\hline 20 & liver/1/16x15x16 right lob & $1 / 512$ & 2.010 & $8 ; 16-18 ; 26-28 ; 56-65$ \\
\hline $21 ; 25^{*}$ & liver/1/ 14x14 & $1 / 4096$ & $2.012 ; 2.125$ & $8 ; 16-18 ; 38 ; 26-28 ; 56-65$ \\
\hline 22 & tibia & $1 / 256$ & 0.764 & 8 \\
\hline $23 ; 24 *$ & liver/1/ 10 left lob & $1 / 2048$ & $2.115 ; 2.1$ & $8 ; 16-18 ; 28 ; 56-65$ \\
\hline 26 & liver & $1 / 128$ & 1.250 & 7,26 \\
\hline $27 ; 30 *$ & liver/1/ right lob 10x7.5; vesica 19x12 & $1 / 256$ & 1.320 & $8 ; 16-18$ \\
\hline 28 & $\begin{array}{c}\text { liver/4/ right lob } 2 \text { cysts } 10 \times 10 \times 14 \\
5 \times 12 \times 9 ; \text { left lob } 2 \text { cysts } 4.5 \times 6 \times 5 ; 2 \times 3 \times 3\end{array}$ & $1 / 256$ & 1.109 & $8 ; 16-18 ; 38 ; 56-65$ \\
\hline 29 & liver & $1 / 4096$ & 1.989 & $7,16,18,26-28$ \\
\hline 31 & pelvic mass, liver mass, over $\mathrm{Ca}$ & negative & negative & negative \\
\hline
\end{tabular}

the first patient with multiple hepatic finding of totally 6 cysts. In this case specific antibodies were detectable only 2 weeks after surgery intervention, with subsequently significant increase. In the second patient a reversal result with decrease of antibody level after surgical treatment was found. In the third patient no specific antibody response was detected. These results suggest that different antibody responses of the patients depend on the individual immune response and localisation or character of the cysts. Our data is comparable to Rigano et al. (1995) who investigated humoral immune parameters which indicate the effectiveness of treatment with respect to the division of the patients on full, partial, low and non-responders.

In the presented study, qualitative and quantitative analy- 
ses of selected sera were performed in comparison with clinical features of the patients. For example, the antigen of approx. $65 \mathrm{kDa}$ was not recognised by sera in the HF antigen of E. granulosus (strips No. 5, 14, 15, 30). The most frequently recognised antigens were those with molecular weights of 8, then fuzzy bands of $16-18$, as well as 24, 26 - $28 \mathrm{kDa}$. Other authors (Yazar \& Altintas, 2003; Turčeková et al., 2004), using hydatid fluid from fertile sheep cysts of E. granulosus, identified different major proteins in the range of $8(12), 16,24,28,38$ and $116 \mathrm{kDa}$. For the species differentiation by the Western blot technique using a whole larval antigen from E. multilocularis, the authors Liance et al. (2000) indicated $97 \%$ of Echinococcus-infected patients. The assay allowed them to distinguish correctly between E. granulosus- and E. multilocularis-infected patients in $76 \%$ of the cases. In the presented study, all the examined patients were from Turkey, which is considered as an endemic area for the occurrence of E. granulosus. From the diagnostic point of view $8 \mathrm{kDa}$ band is sufficient for the determination of specific diagnosis of this serious disease.

In conclusion, there is no "general rule" in the diagnostic approach of CE. Each clinical case must be considered individually according to the internationally accepted recommendations and the physician's personal experience (Pawlowski et al., 2001). A complex approach for the establishing the correct diagnosis is useful. Early diagnosis and subsequent treatment may reduce mortality (Wen et al., 1993; Lightowlers \& Gottstein, 1995; Eckert \& Thompson, 1997).

\section{Acknowledgement}

This study was supported by the Scientific and Technical Research Council of Turkey (SBAG-SLOVAK-1 102S 115), Grant Agency of the Slovak Republic VEGA (No. 2/4179/26) and the grant ŠPVV (No. 2003 SP51/0280800/ 0280803).

\section{References}

Altintas, N., Killi, R., Mentes, A., Yazar, S., YolaSigmaZ, A., SAKrU, N., ERTABAKLAR, H. (1999a): Diagnosis and follow up of human hydatid disease: Serology and radiology. XIX International Hydatidology Congress, 20 - 24 September, 1999, Bariloche, Argentina

Altintas, N., Yazar, S. (1999): Diagnosis of cystic echinococcosis. Acta Tropica Turcica, 23: 160 - 168 (In Turkish)

Altintas, N., Yazar, S., Yolasigmaz, A., Akisü, C., SAKRU, N., KARACASU, F., GÜZElANT, A. (1999b): A seroepidemiological study of cystic echinococcosis in Izmir and its surrounding area, Turkey. Helminthologia, 36: $19-$ 23

Brunetti, E., Filice, C. (2005): Echinococcus hydatid cyst. http://www.emedicine.com/med/topic629.htm

Craig, P. S., Nelson, G. S. (1984): The detection of circulating antigen in human hydatid disease. Ann. Trop. Med.
Parasitol., 78: $219-227$

Craig, P. S., Rogan, M. T., Allan, J. C. (1996): Detection, screening and community epidemiology of teniid cestode zoonoses: cystic echinococcosis, alveolar echinococcosis and neurocysticercosis. Adv. Parasitol., 38: $169-$ 250

ECKert, J., ThOMPson, R. C. A. (1997): Intraspecific variation of Echinococccus granulosus and related species with emphasis on their infectivity to humans. Acta Trop. 64: $19-34$

Force, L., Torres, J. M., CARrillo, A., BuscA, J. (1992): Evaluation of eight serological tests in the diag-nosis of human echinococcosis and follow-up. Clin. Infect. Dis., 15: $473-480$

Garabedian, G. A., Matossian, R. M., Djanian, A. Y. (1957): An indirect haemagglutination test for hydatid disease. J. Immunol., 78: $269-272$

GotTstein, B. (1992): Molecular and immunological diagnosis of echinococcosis. Clin. Microbiol Rev., 5: 248 - 261 GotTstein, B., HeMPhill, A. (1997): Immunopathology of echinococcosis. Chem. Immunol., 66: $177-208$

KinčEKovÁ, J., DubinskÝ, P., Bober, J. Bodo, F., ReITEROVÁ, K. (1996): Differential diagnosis of human echinococcosis and the reasons for its increase incidence. Czech and Slov. Gastroent., 50: 166 - 171 (In Slovak)

LAEMMLI, U. K. (1970): Cleavage of structural proteins during the assembly of the head of the bacteriophage T4. Nature 277: $680-685$

Liance, M., Janin, V., Bresson-Hadni, S., Vuitton, D. A., Houin, R., PiarrouX, R. (2000): Immunodiagnosis of Echinococcus Infections: Confirmatory testing and species differentiation by a new commercial Western blot. J. Clin. Microbiol., 38: $3718-3721$

Lightowlers, M. W., GotTstein, B. (1995): Immunodiagnosis of echinococcosis. In THOMPSON R. C. A., LYMBERY A. J. (Eds.): Echinococcus and hydatid disease. CAB International, Wallingford, UK, pp. $355-410$

Pawlowski, Z. S., Eckert, J., Vuitton, D. A., Amman, R. W., Kern,P., Craig, P. S., DAR, K. F., De Rosa, F., Filice, C., Gottstein, B., Grimm, F., Macpherson, C. N. L., Sato, N., Todorov, T., Uchino, J., Von Sinner, W., WEN, H. (2001): Echinoccosis in human: clinical aspects, diagnosis and treatment. In WHO/OIE Manual on echinococcosis in humans and animals: A public health problem of global concern. ECKERT, J., GEMMEL, M. A., MESLIN, F. X., PAWLOWSKI, Z. S. (Eds), pp. 20 - 71

Ramos, G., OrdunA, A., GARCiA-Yuste, M. (2001): Hydatit cyst of the lung: diagnosis and treatment. World $J$. Surg., 25: $46-57$

Rebhandl, W., Turnbull, J., Felberbauer, F.X., TAsci, E., Puig, S., Auer, H. (1999): Pulmonary echinococcosis (hydatidosis) in children: results of surgical treatment. $\mathrm{Pe}$ diatr. Pulmonol., 27: 336 - 340

Rigano, R., Profumo, E., Ioppolo, S., Notargiacomo, S., Ortona,E., Teggi, A., Siracusano, A. (1995): Immunological marcers indicating the effectiveness of pharmacological treatment in human hydatid disease. Clin. Exp. Immunol., 102: 281 - 285 
TURČEKOVÁ, L., KINČEKOVÁ, J., REGensbogenOvÁ, M., REITEROVÁ, K., DUBINSKÝ, P. (2004): Immunochemical analysis of Echinococcus granulosus and Echinococcus multilocularis antigens. Helminthologia, 41: $179-183$

YAZAR, S., Altintas, N. (2003): Serodiagnosis of cystic echinococcosis in Turkey. Helminthologia, 40: 9 - 13

Zarzosa, M. P., Orduna-Domingo, A., GuTIER-ReZ, P.,

RECEIVED SEPTEMBER 13, 2006
Alonso, P., Cuervo, M., Prado, A. (1999): Evaluation of six serological tests in diagnosis and posto-perative control of pulmonary hydatid disease patiens. Diagn. Microbiol Infect Dis., 35: 255 - 262

Wen, H., New, R. R. C., CRAiG, P. S. (1993): Diagnosis and treatment of human hydatidosis. Br. J. Clin. Pharmac., 35: $565-574$

ACCEPTED OCTOBER 27, 2006 